\title{
Update on the use of rituximab for intractable rheumatoid arthritis
}

\section{R John Looney}

University of Rochester, Rochester, New York, USA
Correspondence: Richard John Looney Professor of Medicine, University of Rochester, Room G-6427C, 595 Elmwood Ave, Rochester, New York 14642, USA

Fax + I 585-275-7|60

Email john_looney@urmc.rochester.edu
This article was published in the following Dove Press journal:

Open Access Rheumatology Research and Reviews

26 June 2009

Number of times this article has been viewed

\begin{abstract}
It has been 3 years since rituximab, a mouse $\mathrm{x}$ human chimeric anti-CD20 monoclonal antibody that selectively depleted B cells, was approved by the FDA for the treatment of moderate to severe rheumatoid arthritis (RA) with an inadequate response to anti-TNF therapies. Since approval rituximab has become a part of standard treatment, and additional data have become available on long-term efficacy and safety both from clinical trials and from post-marketing surveillance. In open long-term follow-up from clinical trials, patients treated with multiple courses of rituximab continued to respond in terms of signs and symptoms, and damage assessed radiographically was significantly inhibited. Moreover, the rate of serious infectious events was not increased as the number of courses increased. However, because of case reports of progressive multifocal leukoencephalopathy in patients treated with rituximab for non-malignant conditions, a black box warning has been added. Studies on the immunologic correlates of response to rituximab treatment including B cell subsets in peripheral blood and synovial biopsies are providing clues into how rituximab works for autoimmune disease. However, at this time we are not able to explain why some patients do not respond and cannot predict who will respond. Future challenges for the further development of rituximab for intractable RA will be discussed.
\end{abstract}

Keywords: rheumatoid arthritis, rituximab, B cells, immunocompetency

\section{What is the rationale for using rituximab in rheumatoid arthritis (RA)?}

Edwards and collaborators hypothesized that rheumatoid factor (RF) containing immune complexes play a major role in the synovial inflammation seen in RA, and that B cell depletion therapy (BCDT) would be an effective therapy for RA by eliminating the autoantibodies producing B cells that perpetuate inflammation. ${ }^{1,2}$ At the time this hypothesis ran counter to the prevailing view that $\mathrm{T}$ cells and innate immunity were the keys to RA. However, immune complexes in synovial fluid and synovial tissue from RA patients were first described back in the 1960s and the importance of these immune complexes in synovial inflammation has long been appreciated. ${ }^{3} \mathrm{IgG}-\mathrm{RF}$ may play a special role in the pathogenesis of RA. By failing to fix complement small circulation IgG-RF complexes escape clearance by the reticuloendothelial system, then pass through the fenestrated capillary endothelium of synovial tissue (which resembles the endothelium seen in glomeruli, ciliary body, choroid plexes, and intestinal villi) and deposit in the synovium. ${ }^{3}$ These complexes can then bind to synovial leukocytes via Fc $\gamma R$ s leading to cellular activation and secretion of TNF $\alpha$ and IL-1. Thus, IgG-RF provides a link between autoantibodies and the production of cytokines that have 
been targeted for the treatment of RA. ${ }^{4}$ Mouse models have been used to demonstrate that IgG from patients from plasma of with RA patients but not controls is able to induce synovitis. ${ }^{5}$ In addition, anti-CCP antibodies have been shown to augment collagen-induced arthritis. ${ }^{6}$ These studies provide abundant evidence supporting a role for autoantibodies and immune complexes in the pathogenesis of RA synovitis. Of course, plasma cells do not express CD20 so rituximab should not directly target plasma cells. Therefore, the effect of rituximab on autoantibodies are probably indirect, ie, blocking the generation of new autoantibody-secreting plasma cells by killing precursors, or by decreasing synovial inflammation and disrupting the microenvironment required for plasma cell survival. ${ }^{7}$

Alternatively, the effects of rituximab may be related to the activities of $\mathrm{B}$ cells that are independent of antibody secretion. B cells can produce a variety of cytokines. Depending on which B cell subset is studied and how B cells are stimulated either pro-inflammatory cytokines such as lymphotoxin, TNF, and $\gamma$ interferon, or anti-inflammatory cytokines such as IL-10 may be produced. ${ }^{8-10}$ In addition, B cells can help organize infiltrating leukocytes and induce lymphoid neogenesis by recruiting and activating follicular dendritic cells. ${ }^{11-13} \mathrm{~B}$ cells regulate $\mathrm{T}$ cells not only through cytokine secretion but also by acting as highly efficient antigen presenting cells. Indeed, B cells unable to severe immunoglobulins have been found to be critical in a mouse model of inflammatory arthritis. ${ }^{14}$ Moreover, using human synovial tissue transplanted into immunodeficiency mice which were then treated with rituximab, the importance of synovial B cells for T cell activation in RA has been demonstrated. ${ }^{15}$

In many diseases both autoantibody production and autoantibody independent effects for B cells are likely to be important. For example, a dual effect of rituximab on pemphigus vulgaris has been shown. Rituximab treatment decreases not only autoantibody levels but also autoantigenspecific T cell responses. ${ }^{16}$ Similarly, although generating autoantibody secreting plasma cells is undoubtedly important in RA, inhibition of autoantibody independent function of B cells may also be important. These autoantibody independent functions of B cells would almost certainly be the targets of rituximab in seronegative RA.

\section{Efficacy of rituximab in RA}

Approval of rituximab for signs and symptoms of RA was based on efficacy in 3 double blind placebo-controlled, randomized clinical trials (Phase IIa, DANCER, REFLEX). ${ }^{17-19}$ The Phase IIa trial established the efficacy of rituximab ( $1 \mathrm{~g}$ on days 1 and 15), and demonstrated that the cyclophosphamide used in the original open trial ${ }^{20}$ was not necessary and that methotrexate was the best concomitant medication. Benefits from a single course of rituximab were highly significant at 24 weeks and persisted at 48 weeks especially in the group that received methotrexate. DANCER established that the high dose steroids used in the original open trial did not contribute to efficacy but that pre-medication with IV steroids reduced infusion reactions modestly. In DANCER $500 \mathrm{mg}$ and $1000 \mathrm{mg}$ for rituximab on days 1 and 15 appeared to be about equally effective. The REFLEX trial tested efficacy in patients with an inadequate response to anti-TNFs both in terms of signs and symptoms and in terms of radiographic joint damage. The number of patients who had failed anti-TNF therapy was not mentioned in the IIa study and represented only about one third of the patients in DANCER. Therefore, the REFLEX trial is the best data we have for the efficacy of rituximab in patients who are "intractable".

In the REFLEX trial patients on a stable dose of methotrexate were randomized to either rituximab $1000 \mathrm{mg}$ or placebo iv on days 1 and 15 . All patients received $100 \mathrm{mg}$ methylprednisolone prior to each infusion and additional oral glucocorticoids (60 mg prednisone days 2 to 7 and $30 \mathrm{mg}$ days 8 to 14 ) between the two infusions. The primary endpoint was the ACR20 response rate at 24 weeks. A total of 520 patients were randomized, and 499 patients were in the intention-to-treat analysis, 298 received rituximab and 201 received placebo. At 24 weeks there was a statistically significant improvement not only in the ACR20 (ACR, American College of Rheumatology), but also in the ACR50, and ACR70 in the patients who received rituximab $(P$ values $<0.001)$ (see Table 1$)$.

Table I Clinical response in the REFLEX trial

\begin{tabular}{lll}
\hline & $\begin{array}{l}\text { Rituximab } \\
(\mathbf{n}=\mathbf{2 9 8})\end{array}$ & $\begin{array}{l}\text { Placebo } \\
(\mathbf{n}=\mathbf{2 0} \text { I) }\end{array}$ \\
\hline ACR response & & $18(12-26)$ \\
ACR 20 & $5 \mathrm{I}(44-58)$ & $5(2-10)$ \\
ACR 50 & $27(21-34)$ & $1(0-4)$ \\
ACR 70 & $12(8-18)$ & \\
EULAR response & & $20(13-28)$ \\
Moderate & $50(43-57)$ & $2(0-6)$ \\
Good & $15(10-21)$ & $2(0-6)$ \\
Low disease & $15(10-21)$ & $0(0-3)$ \\
Remisson & $9(5-14)$ & \\
\hline
\end{tabular}

Note: Results are shown as \% response ( $99 \%$ confidence interval). 
The REFLEX trial also assessed joint damage using the Genant-modified Sharp Score for radiographic progression. From baseline to 56 weeks treatment with rituximab was associated with significantly decreased change in Total Sharp Score, the erosion score, and the score for joint narrowing (see Table 2). ${ }^{21}$ A new report indicates that the differences in radiographic damage between the rituximab-treated and placebo-treated patients persists when re-evaluated at week 104, total Sharp Score was 1.14 for rituximab-treated patients and 2.81 for placebo-treated patients $(P<0.0001) .{ }^{22}$ An unanswered question is whether the high dose steroids used in REFLEX plays any role in protection from radiographic damage, ie, would rituximab without such high dose steroids be as effective?

In the REFLEX trial fewer rituximab-treated, RF-negative patients achieved an ACR20 at week 24 than RF-positive patients achieved an ACR20 response at week 24 (41\% RF-negative vs 54\% RF-positive) but there was also a lower placebo response (12\% RF-negative vs 19\% RF-positive). The differences in ACR20 between rituximab- and placebo-treated patients was highly significant for both the RF-negative and RF-positive groups $(P<0.0009$ and $<0.0001$, respectively).

In open trials rheumatoid factor and anti-CCP antibodies were found to decrease with rituximab therapy. ${ }^{23,24}$ A moderate decrease in autoantibodies has been confirmed in randomized trials, ie, comparing baseline to 24-week titers in the REFLEX trial RF levels decreased by $55 \%$ in rituximab-treated patient and increased 37\% in placebotreated patients. ${ }^{19}$

\section{Re-treatment with rituximab}

The safety and efficacy of re-treatment with rituximab for RA has not been established. The original trials leading to the approval of rituximab for RA do not provide controlled data on re-treatment. However, many patients in those clinical trials entered into open-label extension trials. Patients in the REFLEX trial were eligible for an open-label trial with repeated dosing. The patients who received placebo were

Table 2 Structural damage in the REFLEX trial

\begin{tabular}{llll}
\hline & $\begin{array}{l}\text { Rituximab } \\
(\mathbf{n}=\mathbf{2 7 3})\end{array}$ & $\begin{array}{l}\text { Placebo } \\
(\mathbf{n}=\mathbf{1 9 8})\end{array}$ & P value \\
\hline Total & $\mathrm{I}$ & 2.31 & 0.005 \\
Narrowing & 0.41 & 0.99 & 0.001 \\
Erosions & 0.59 & 1.32 & 0.011 \\
\hline
\end{tabular}

Note: Results are given as mean sharp score. allowed to go on rituximab as part of this open label extension. Data for 179 patients receiving at least 3 courses indicates continued efficacy. ${ }^{25}$ Of course, this group of patients was undoubtedly biased because patients who did poorly could opt out of further treatment. Nevertheless, it is interesting to note that there was a subset of patients who continued to respond to repeated courses of rituximab and that in this group the proportion of patients with very good responses increased over time, ie, for 179 patients who received 3 courses of rituximab and had ACR responses assessed at 24 weeks post each infusion, the proportion of patients with an ACR70 increased from $14.0 \%$ after the first course to $25.7 \%$ after the third infusion $(P=0.0049)$. Similarly, for the 170 patients treated with 3 courses and assessed with European League Against Rheumatism (EULAR) scores, $17.1 \%$ had low disease activity (DAS28 $\leq 3.2$ ) (DAS, Disease Activity Score in Rheumatoid Arthritis) after the first infusion, $25.9 \%$ had low disease activity after the second infusion and $34.1 \%$ had low disease activity after the third infusion $(P<0.05$ for 1 st vs 2 nd course; $P<0.00001$ for first vs third course).

There have been two publications that provide some preliminary data on what to do for patients who do not respond to the first course of rituximab. A publication from Amsterdam reported on re-treatment of 6 patients who were non-responders to the initial course of rituximab compared to 16 patients who were responders to the initial course. Patients treated with an initial course of rituximab were re-treated after an interval of at least 6 months if they had a DAS28 $>3.2 .{ }^{26}$ All 6 non-responders to the initial treatment were non-responders to re-treatment by EULAR criteria. In contrast, of the 16 responders to initial treatment, 4 were EULAR good responders, 10 were EULAR moderate responders, and only 2 were EULAR non-responders. These data suggest that patients who do not respond to the initial course of rituximab should not receive a second course. However, the numbers are small and there was not a statistically significant difference in the proportion of responders ( 0 of 6 vs 14 or $16, P=0.36$ by chi-squared analysis) between the two groups. A second report on re-treatment of non-responders was recently presented. ${ }^{27}$ In 14 non-responders the DAS28 improved by only 0.75 at 16 weeks after the initial course of rituximab. At 16 weeks following re-treatment the cumulative improvement for these initial non-responders (initial baseline to post second course) was 1.23. Anti-CCP positive patients had somewhat better cumulative response than anti-CCP negative patients, 2.24 vs 1.14 . Based on this study it appears possible that a 
subgroup of non-responders may improve after a second course. However, both of these studies were small. Therefore, the question of re-treating non-responders remains open and needs further study.

Another question is whether re-treatment should be given at fixed times or when it is needed. Two centers, one giving rituximab every 24 weeks and one giving re-treatment as disease relapse, studied 48 patient is a prospective, open, non-randomized trial. ${ }^{28}$ There was no difference in ACR response, EULAR response, changes in DAS28, Health Assessment Questionnaire (HAQ) score, or radiographic progression. While the results are very interesting there are several problems with the study: 1) The open, non-randomized design does not protect against bias. 2) The segregation of treatment groups by center does not protect against differences in how the two centers treat and assess RA. 3) The follow-up was only 1 year which is certainly too brief to adequately assess efficacy, because patients would only be re-treating once. 4) The numbers are very small. Nevertheless, the authors identified a timely and very important question that needs further investigation.

An international group of rheumatologists published their recommendations on the use of rituximab for RA in 2007. ${ }^{29}$ They recommended consideration of re-treatment only after 24 weeks for patients continuing to have moderate disease activity (DAS > 3.2), or for patients who responded to rituximab but then deteriorated clinically. The definition of clinical deterioration was left open. This report did not make recommendations on what to do with patients ho failed to respond to the initial course of rituximab.

\section{Effects of rituximab on B cell homeostasis}

Treatment of RA patients with rituximab leads to rapid and prolonged depletion of peripheral blood $B$ cells that persist for months, ie in the phase IIA, DANCER, and REFLEX trials B cells had barely become detectable at 24 weeks. ${ }^{17-19}$ Residual CD19+ cells during the period of marked depletion are predominantly memory B cells (CD19+, IgD-, CD27+) and plasma cells (CD19+, IgD-, CD38high). ${ }^{30}$ With reconstitution IgD+CD27- predominate. These CD27-B cells are a mixture of mature naïve B cells (CD19+, IgD+, CD38+) and immature transitional B cells (CD19+, IgD+, CD38high, CD10+, CD24high). ${ }^{31}$ The number of memory $\mathrm{B}$ cells recovers more slowly and may still be low even years later. On the average IgA and IgG levels and levels of protective antibodies change very little after rituximab, indicating that plasma cells are spared. ${ }^{18}$ In contrast IgM levels decrease markedly ie around 50\%. It has been speculated the decrease in IgM may be related to depletion of non-switched memory B cells $(\mathrm{IgD}+\mathrm{CD} 27+)$ which responsible for the synthesis of "natural" antibodies and provide a rapid response to blood-borne pathogens. ${ }^{32}$ Presumably the plasma cells induced by these non-switched memory $\mathrm{B}$ cells would have to have a relatively short half life to account for the drop in IgM. B lymphocyte stimulator (BLyS or BAFF) and a proliferation-inducing ligand (APRIL) regulated B cell homeostasis. With B cell depletion BLyS levels increase dramatically in patients with RA. ${ }^{24,33}$ Presumably the loss of B cells in secondary lymphoid tissue prevents consumption of BLyS and elevated BLyS levels may be an indirect gauge how successful B cell depletion has been in tissues.

Clinical response after treatment with rituximab has also associated with very complete depletion of peripheral blood B cells after the initial infusion, and relapse has been associated with recovery of B cells, especially memory $\mathrm{B}$ cells and plasmablasts.

- An early study from London reported that patients with early relapse tended to reconstitute with increased numbers of memory (CD27+) B cells. ${ }^{30}$

- A subsequent German study also found that non-switched, memory B cells (CD19+IgD+CD27+) at the time of B cell recovery were significantly higher in non-responders, and responders who relapsed early had higher baseline levels of total memory B cells (CD19+CD27+) ${ }^{32}$

- A publication from Leiden supports a relationship between low disease activity and slow recovery of peripheral blood B cells. At 24 weeks the frequency of CD19+ lymphocytes (total B cells) was significantly lower in patients with low disease activity. At that time CD19+IgD+ B cells (presumed to be mostly naïve but non-switched memory would also stain with these markers) was $0.044 \%$ in low activity patients vs $0.45 \%$ in high activity patients $(P=0.006)$, and the frequency of switched memory B cells (CD19+CD27+) was $0.17 \%$ in low activity patients vs $0.67 \%$ in patients with high disease activity $(P=0.005){ }^{34}$

- An important study from Leeds found very early complete depletion of B cells was related to overall clinical efficacy. In prior studies complete B cell depletion had been defined as less than 5 cells $/ \mu \mathrm{L}\left(<0.005 \times 10^{9}\right.$ cells $\left./ \mathrm{L}\right)$, but using a highly sensitive assay the Leeds group defined depletion of $\mathrm{B}$ cells as less than 0.01 cells $/ \mu \mathrm{L}$ $\left(<0.00001 \times 10^{9}\right.$ cells $\left./ \mathrm{L}\right)$, ie, about 50 times lower than the standard definition. With this more stringent definition $82 \%$ of patients with complete depletion after 
the first infusion with rituximab had a moderate or good EULAR response at 9 months compared to $43 \%$ of patients with incomplete depletion $(P<0.01)$. Similarly, at 12 months $59 \%$ of good depleters had a moderate or good EULAR response compared to $21 \%$ of patients with incomplete depletion $(P<0.01){ }^{35}$

- A recent presentation reported that after treatment with rituximab the number of plasmablasts/early plasma cells in peripheral blood (CD19+, CD201o, CD27high) correlated remarkably with DAS28 score $\left(r^{2}=0.64\right.$, $P=0.0019){ }^{36}$

In animal studies treatment with anti-CD20 completely depletes B cells from peripheral blood, but there are lymphoid tissues where $\mathrm{B}$ cell depletion can be less incomplete, ie, the marginal zone in the spleen and Peyer's patches in the gut. ${ }^{37}$ Mobilization of tissue $B$ cells to ensure migration through the circulation, or neutralization of B cell growth factor results in anti-CD20 depletion from these sites. Similarly, in patients with RA treated with rituximab biopsy studies have shown variable depletion of synovial B cells. ${ }^{38-40}$ Despite the fact that rituximab only targets $B$ cells changes in the number of synovial $\mathrm{T}$ cells and macrophages have also been found, and at even later times after treatment with rituximab changes in the number of synovial plasma cells have been seen.

- In a study from Amsterdam synovial B cells at 16 weeks post rituximab correlated with the number of synovial plasma cells, T cells, and macrophages $(r=0.70,0.69$, and 0.72 respectively; $P<0.001$ for each correlation). In addition, the change in synovial plasma cells and macrophages between weeks 4 and 16 correlated significantly with clinical response at 24 weeks, $r=0.46$ with $P=0.003$ for plasma cells, and $\mathrm{r}=0.51$ with $P=0.04$ for macrophages. (For unclear reasons, the change from baseline to 16 weeks did not correlate with clinical response). Thus, these preliminary studies demonstrate that changes in synovial cells are associated with clinical responses to rituximab. ${ }^{41}$

- A very recent study from Leiden found that low numbers of synovial CD79a+ B cells at 12 weeks post treatment was associated with low disease activity. Histological score for CD79a+ B cells was 0.33 in low activity disease, and 1.33 in high activity disease, $P=0.0016$. These CD79a+ cells were CD20- and CD138-; the authors felt they might represent a type of plasma cell. ${ }^{34}$

The correlation between decreases in synovial plasma cells and clinical response after rituximab therapy is particularly interesting. The original hypothesis justifying
B cell depletion therapy in RA postulated just such a relationship reasoning that the driving force in RA was synovial synthesis of autoantibodies, formation of immune complexes, and induction of cytokines via interaction between immune complexes and Fc $\gamma$ Rs on macrophages. Decreased numbers of synovial plasma cells may also be an important in the selective decrease in rheumatoid factors and anti-CCP antibodies with treatment. If the autoantibodies associated with RA are selectively produced by synovial plasma cells, then treatment of inflammation leading to loss of synovial plasma cells should result in selective decrease in these autoantibodies. An early attempt to demonstrate such a relationship was unsuccessful but the samples studied were at 8 weeks post treatment, ${ }^{42}$ Based on the studies from Amsterdam 8 weeks may have been too early to see a decrease in synovial plasma cells.

\section{Safety}

There are currently four black box warnings for rituximab: 1) fatal infusion reactions, 2) tumor lysis-syndrome, 3) severe mucocutaneous reactions, and 4) progressive multifocal leukoencephalopathy (PML).

- Infusion reactions continue to be a problem with all intravenously administered immunoglobulins. Rituximab appears to have more of a problem than other biologics especially with the first infusion. This is presumably because rituximab can complex with circulating B cells triggering Fc $\gamma \mathrm{R}$-mediated or complement mediated reactions. Apart from the presence of protein aggregates, the most important factor for infusion reactions to intravenous immune globulin (and presumably other biologics) is the rate of infusion. ${ }^{43}$ As personnel in infusion centers have become better at recognizing early infusion reaction and stopping the infusion before problems escalate, infusion reactions have become less of a problem in many centers, but vigilance and preparation to treat reactions are still important. Pre-medication with acetaminophen and anti-histamine is recommended in the prescribing information, and pre-medication with iv methylprednisolone was shown to be of some benefit in steroids was of some benefit in controlled trials. ${ }^{18}$ After a patient experiences an infusion reaction there is often a refractory period with relative protection from infusion reactions for several days. ${ }^{43}$ Thus, if an infusion is halted because of an infusion reaction and not restarted during the same session, we have recommended that re-treatment (if indicated) should be attempted within a few days. 
- Tumor lysis syndrome (TLS) after treatment with rituximab is associated with rapid lysis of B cells in patients with a large burden of disease. At this time there are no reports of TLS in patients with non-malignant disease treated with rituximab. However, we have seen a patient with RA-associated Castleman's syndrome who developed TLS after treatment with rituximab. (RJ Looney, unpublished). Therefore, precautions should be taken to prevent TLS.

- Multiple cases of severe mucocutaneous reactions with rituximab have been reported in the oncology literature but have not been reported in non-malignant conditions. Some of these cases have been paraneoplastic pemphigoid which would not be seen in non-malignant diseases, but a variety of other rashes have been seen including toxic Stevens-Johnson and epidermal necrolysis. ${ }^{44}$ Although a causal relationship is often unclear for some cases the timing has been very suggestive. Moreover, two rhesus monkeys treated with rituximab developed a blistering skin eruption that recurred on re-treatment. ${ }^{45}$ On the other hand, rituximab is being used for a number of blistering skin conditions. ${ }^{16,46}$ Despite the relatively low risk, this warning still needs to be discussed with patients.

- $\quad$ PML is a demyelinating central nervous system (CNS) infection with the John Cunningham virus (JC virus), a human polyoma virus. JC virus is contracted in childhood as an asymptomatic infection, and $80 \%$ of adults are seropositive for JC virus. ${ }^{47}$ In healthy individuals, the $\mathrm{JC}$ virus is carried as a latent infection with periodic viral shedding in the urine without any clinical sequelae. When profound immunosuppression or immunodeficiency compromise the host defense, JC virus can reactivate and cause CNS disease by infecting the myelin-producing oligodendrocytes. PML has been reported in recipients of organ transplantation, patients undergoing chemotherapy, and patients with HIV infection. Patients receiving biologic therapies for autoimmunity have also developed PML. At least 7 patients with multiple sclerosis or Crohn's disease have developed PML while being treated with natalizumab. ${ }^{48-51}$ More recently, 4 patients taking efalizumab, an anti-LFA1 monoclonal antibody, for psoriasis developed PML. All of these patients were on efalizumab for more than 3 years. As a result of these cases efalizumab was voluntarily pulled from the US market in April 2009. 52 PML has also been reported in lymphoma patients undergoing treatment with rituximab. Nearly all these patients have received rituximab in combination with chemotherapy or stem cell transplantation. ${ }^{53-56}$ However, PML has now been reported in 2 systemic lupus erythematosus (SLE) patients and 1 RA patient treated with rituximab. ${ }^{57-59}$ The two SLE patients with PML after rituximab had received prior treatment with immunosuppressive medications, including cyclophosphamide. The RA patient's last dose of rituximab was 18 months prior to developing PML. The patient developed tonsilar carcinoma and received radiation and chemotherapy in the months just prior to developing PML. Recent review of PML in patients with rheumatologic disease who never received rituximab found that most patients with PML had SLE. ${ }^{60,61}$ Interestingly, about $40 \%$ for the patients with PML and SLE received minimal immunosuppressive therapies suggesting that immunosuppression from SLE itself may play a role in reactivation of JC virus. At this point there needs to be considerable concern about PML in patients on biologic therapies. ${ }^{62}$ The evidence for a direct causal effect between treatment with natalizumab or efalizumab and PML is quite strong since patients with multiple sclerosis and psoriasis are not predisposed to PML based on their underlying disease. The case for a link between rituximab and PML is still uncertain because of the background increased risk in patients with SLE.

Immunosuppression is a significant problem in patients treated with biologics. Guidelines from the Autoimmunity Centers of Excellence for the evaluation of immunocompetency in clinical trails have recently been published as has a review on the effects of rituximab on immunocompetency. ${ }^{63,64}$

The rate of serious infection using pooled data from the phase IIa, DANCER, and REFLEX trials was 5.0 per 100 patient-years in the group receiving rituximab and 3.4 per 100 patient-years in the group receiving placebo $(P=0.49)$, but the number of patients available was too small to detect even a doubling of the infection rate. ${ }^{64} \mathrm{~A}$ meta-analysis of serious infections in RA patients treated with rituximab has recently been published. ${ }^{65}$ A total of 745 rituximab treated patients were compared to 398 controls. The pooled odds ration for risk of serious infection with rituximab vs placebo was 1.45 with a $95 \%$ confidence interval (CI) of 0.56 to 3.73 ). Patients were broken down into those that received high dose rituximab (1000 mg per dose) versus low dose rituximab. The odds ratio for high dose rituximab vs placebo was 1.68 (95\% CI 0.64 to 4.35 ), and the odds ratio for low dose rituximab vs placebo was 0.24 (95\% CI 0.01 to 4.33$)$. This new analysis confirms that an increased risk of serious infection with rituximab was not seen with the available data, but this analysis also suffers from a lack of power (see Table 3 for calculations of the group size needed to be to have sufficient 
Table 3 Group size to have an $80 \%$ power $(\beta=0.80)$ of detecting a significant $(\alpha=0.05)$ increase in the rate of serious infection

\begin{tabular}{lllll}
$\begin{array}{l}\text { Infection rate } \\
\text { in placebo } \\
\text { controls }\end{array}$ & $\begin{array}{l}\text { Infection rate } \\
\text { increased by } \\
\mathbf{2 \%} \text { with } \mathbf{R x}\end{array}$ & $\begin{array}{l}\text { Infection rate } \\
\text { increased by } \\
\mathbf{3 \%} \text { with } \mathbf{R x}\end{array}$ & $\begin{array}{l}\text { Infection rate } \\
\text { increased by } \\
\mathbf{4} \% \text { with } \mathbf{R x}\end{array}$ & $\begin{array}{l}\text { Infection rate } \\
\text { increased by } \mathbf{5 \%} \\
\text { with } \mathbf{R x}\end{array}$ \\
\hline $2 \%$ & 1240 & 655 & 425 & 310 \\
$3 \%$ & 1605 & 815 & 515 & 365 \\
$4 \%$ & 1965 & 975 & 605 & 420 \\
$5 \%$ & 2315 & 1125 & 690 & 475 \\
\hline
\end{tabular}

Abbreviation: $\mathrm{Rx}$, rituximab.

power to detect a $2 \%, 3 \%, 4 \%$, or $5 \%$ increase in the rate of serious infectious events when the rate of serious infections in the control group is $2 \%, 3 \%, 4 \%$, or $5 \%$ ).

Data from RA patients treated with rituximab in open long-term extension studies has been published and this data has recently been updated. ${ }^{66}$ The total number of patientyears follow-up were 2456 for patients receiving 1 course, 1890 for 2 courses, 1043 for 3 courses, 425 for 4 courses and 133 for 5 courses. The serious infection rate per 100 patient years $(95 \% \mathrm{CI})$ was 4.48 (3.77 to 5.40$)$ for 1 course, 3.81 (2.96 to 4.91) for 2 courses, 4.84 (3.40 to 6.88) for 3 courses, 3.79 (1.97 to 7.28) for 4 courses and 6.83 (2.84 to 16.40) for 5 courses. Based on this analysis there does not appear to be an increase in the risk of infection with subsequent courses, but once again the numbers are small especially at the latter time points, and patients who did develop problems might have been more likely to drop out.

The risk of rituximab in patients infected with hepatitis $\mathrm{B}$ and hepatitis $\mathrm{C}$ viruses deserve special consideration. Reactivation of hepatitis B with chemotherapy or immunosuppression is a major clinical problem. For example, in patients $\mathrm{HBsAg}$-/anti-HBc+ patients with non-Hodgkin lymphoma, hepatitis $B$ reactivated in 5 or 21 patients treated with rituximab $+\mathrm{CHOP}$, but in 0 of 41 patients treated with CHOP. ${ }^{67}$ Prophylactic treatment with lamovidine has been used to prevent viral reactivation in patients with malignancies undergoing chemotherapy. ${ }^{68-70}$ In patients with rheumatic diseases treated with biologics or immunosuppressive agents there are similar concerns about viral reactivation and a similar strategy for prophylaxis has been advised. ${ }^{71} \mathrm{HBsAg}+$ patients are at the highest risk but $\mathrm{HbsAg-/anti-HBc+}$ are also at some risk. Hepatitis $\mathrm{C}$ seems to be less of a problem for rituximab therapy. Indeed, rituximab is beneficial in the treatment of hepatitis $\mathrm{C}$ cryoglobulinemia. ${ }^{72,73}$

RA patients treated with rituximab generally have relatively modest $(<10 \%)$ decreases in IgG and IgA, and more significant decreases $(\sim 50 \%)$ in IgM. ${ }^{18}$ In follow-up of 37 patients treated for $>3$ years with up to 5 cycles of B cell depletion therapy, including 22 cases who also received cyclophosphamide, $32 \%, 19 \%, 3 \%$ developed low levels of $\operatorname{IgM}, \operatorname{IgG}$, and $\operatorname{IgA}$, respectively. ${ }^{74}$ In this series hyogammaglobulinemia was associated with a lower respiratory infection in only one patient. In industry-sponsored long-term follow-up of $>1000$ patients low levels of IgM develop in $20 \%$ of patients and low levels of IgG are seen in 5\% of patients. ${ }^{66}$ The rate of serious infections was 4.7 per 100 patient-years for patients with normal IgM and IgG levels, 5.6 per 100 patient-years for patients with low IgM levels, and 4.8 per 100 patient-years in patients with low IgG suggesting that most patients with immunoglobulin levels below normal limits will not have an increased infection rate. ${ }^{66}$ Of course, most of these patients would not have had very low IgG levels. Other factors to consider when determining the risk of low $\operatorname{IgG}$ levels include increased age, extra-articular manifestations of RA, leukopenia, comorbidities (chronic lung disease, alcoholism, organic brain disease, and diabetes mellitus), and use of corticosteroids, which have all been linked in epidemiologic studies to the risk of infection in patients with RA. ${ }^{75-77}$ Measuring antibodies against specific microbial antigens and determining response to immunizations may also play a role in determining risk of low $\operatorname{IgG} .^{78}$

Since rituximab depletes B cells, failure of the humoral immune system to respond to vaccines is not unexpected. Early studies with non-human primates treated with rituximab first demonstrated such a defect and this was subsequently confirmed in patients with lymphomas, end stage renal disease on dialysis, and lupus. ${ }^{79-82} \mathrm{~A}$ very small but interesting study showed that RA patients immunized with influenza vaccine 12 weeks after treatment with rituximab had a markedly decreased antibody response. ${ }^{83}$ In RA patients immunized with influenza vaccine at various times after treatment with rituximab responded but less well than control RA patients. ${ }^{84}$ A large randomize trial of vaccine responses in patients with active RA has recently been presented. ${ }^{85}$ Rituximab-treated and control patients had a comparable recall response to tetanus toxoid at 24 months. At that time 
B cells were still depleted in most patients. At 28 weeks and 32 weeks, respectively, the response to pneumovax and keyhole limpet hemocyanin were significantly lower in the rituximab-treated patients compared to controls. Thus, by 6 months the recall response to a $\mathrm{T}$ cell-dependent antigen returned, but responses to $\mathrm{T}$ cell-independent antigens and primary response to a neoantigen were still depressed.

Neutropenia after treatment with rituximab can occur transiently at the time of infusion but a more serious late onset neutropenia (LON) may develop months after treatment. In a controlled trial of rituximab in combination with chemotherapy for B cell lymphoma LON was detected in 6 of 76 patients receiving rituximab and 0 of 54 patients not receiving rituximab $(P=0.04) .{ }^{86}$ Onset occurred at an average of 175 days post rituximab treatment and lasted an average of 2 weeks. The median neutrophil count for the patients who developed LON was 200 and the lowest counts were 23 and 32. One patient developed a buccal cellulitis. Neutropenia responded to treatment with growth factors. A single case of LON in a patient receiving rituximab in combination with methotrexate for RA has recently been reported. ${ }^{87}$ Routine monthly laboratory studies discovered a neutrophil count of 40 cell $/ \mu \mathrm{L} 3$ months after treatment. The patient had maturation arrest on bone marrow aspirate. She was given two doses of C-CSF and recovered uneventfully.

Although rituximab is effective in RA, many patients treated with rituximab will not have an adequate response and therefore will have to move on to alternative treatments. Since the effects of rituximab are long-lasting, there is concern about additional risk when patients who have failed rituximab start new therapies. Since rituximab is already used with methotrexate, many rheumatologists would feel comfortable switching from methotrexate to leflunomamide whose toxicity profile is fairly close to methotrexate's, but there is more concern with the use of additional biologics. There are some data on the use of anti-TNFs after rituximab from safety follow-up of company sponsored trials. At the latest update 185 patients received other biologics after rituximab. ${ }^{88}$ The serious infection rate before and after starting other biologics were compared. The median time from treatment with rituximab to starting the other biologics was 4 months. The new biologics were anti-TNFs $(n=150)$, abatacept $(n=25)$, and anakinra or experimental biologics $(\mathrm{n}=10)$. The serious infection rate was $6.99(95 \%$ CI 4.06 to 12.03 ) before starting other biologics and 5.49 (95\% CI 2.95 to 10.19 ) after starting other biologics. The lack of any numeric increase of the serious infection rate is somewhat reassuring but the confidence intervals are wide.

\section{Use of rituximab in methotrexate inadequate responders}

Rituximab is approved for anti-TNF inadequate responders but occasionally patients are unable to take anti-TNFs. A series of 39 patients failing disease-modifying antirheumatic drugs (DMARDs) and unable to obtain anti-TNFs were treated with rituximab as their first biologic. ${ }^{89}$ Patients received two intravenous infusions of either $500 \mathrm{mg}$ or $1000 \mathrm{mg}$ rituximab given 2 weeks apart. At 6 and 12 months EULAR response criteria were met in $76 \%$ and $77 \%$ of patients, respectively, and good EULAR response were 36\% and $50 \%$ at the same time points. Since then the results of the SERENE trial have been presented. ${ }^{90}$ In this double-blind, placebo-controlled, randomized trial EULAR response criteria were met at 24 weeks in $34 \%$ of placebo patients, $67 \%$ of patients treated with $2 \times 500 \mathrm{mg}$ rituximab, and $64 \%$ for patients treated with $2 \times 1000 \mathrm{mg}$ rituximab $(P<0.0001$ for either rituximab group vs placebo). ACR20/50/70 were $23 \% / 9 \% / 5 \%$ for placebo, $55 \% / 33 \% / 9 \%$ for $2 \times 500 \mathrm{mg}$ rituximab, and $51 \% / 26 \% / 10 \%$ for $2 \times 1000 \mathrm{mg}$ rituximab. The results of rituximab as first-line biologic for treatment of signs and symptoms were good, but additional studies are needed especially to determine the effects on damage. The ideal study would be a head-to-head comparison of rituximab vs an anti-TNF with follow-up going out to 1 and 2 years to assess radiographic progression.

\section{Challenges}

1. What is the relationship between $B$ cell depletion and clinical efficacy? Circulating memory B cells and plasmablasts are associated with relapse and synovitis. One possibility is that these cells are generated in secondary lymphoid tissue and home to the synovium where they induce inflammation, but an alternative possibility is that memory B cells and plasmablasts are generated in the synovium and then re-circulate into peripheral blood. Of course these possibilities are not mutually exclusive, and we favor the view that B cells trafficking into and out of the synovium are important for maintenance of synovial inflammation (see Figure 1).

2. What determines how effectively B cells are depleted? In peripheral blood rituximab levels and $F c \gamma R$ polymorphisms are important factor in determining $\mathrm{B}$ cell depletion. ${ }^{91}$ However, B cells may "hide" in tissue where the microenvironment may favor survival both because of defective effector mechanisms such as the blockade of Fc $\gamma$ Rs by immune complexes, and because the production of pro-survival factors such as BLyS prevents B cell 


\section{Peripheral blood}

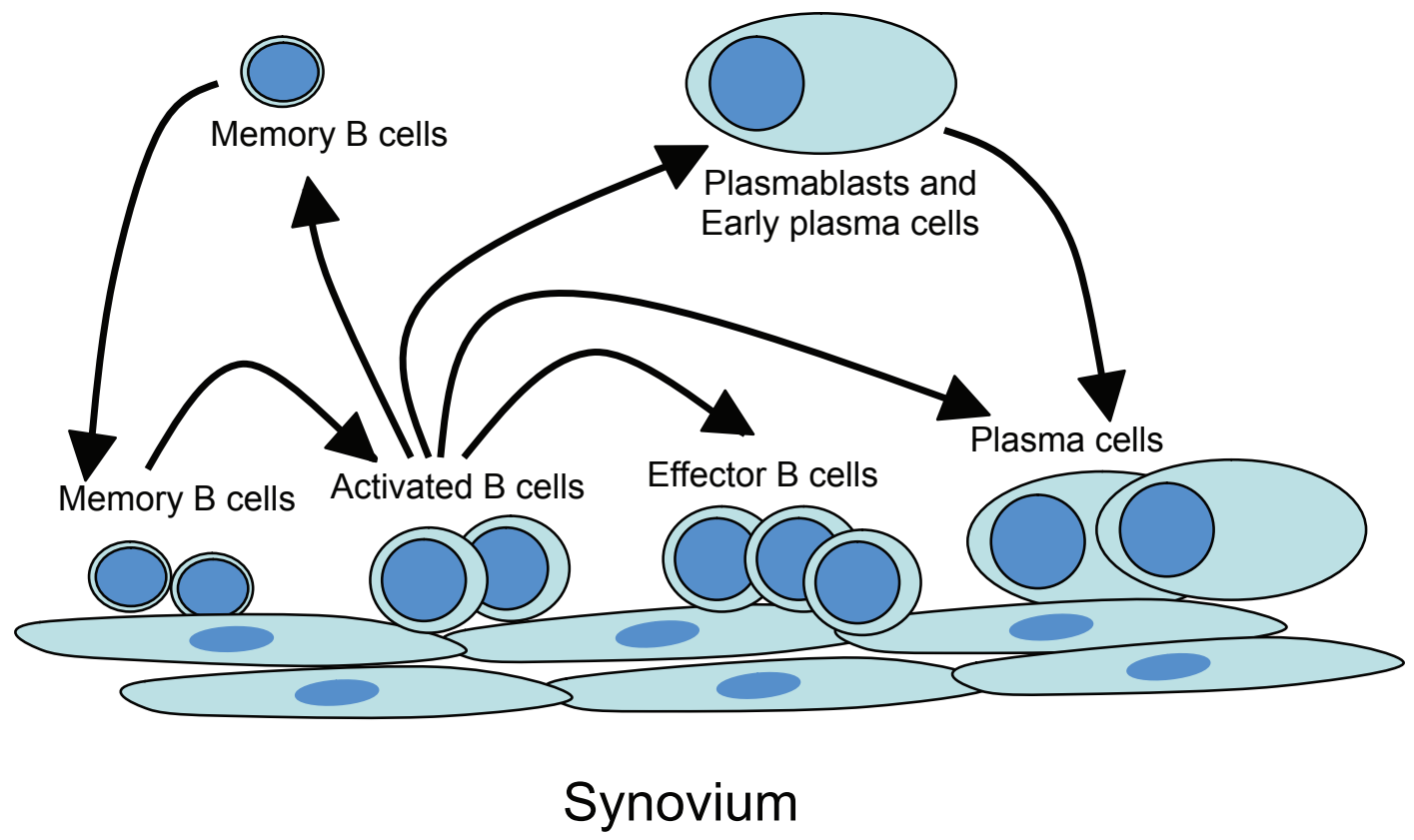

Figure I Recirculation of memory B cells and plasmablasts/early plasma cells from synovium to peripheral blood and back again.

apoptosis. Synergy between anti-CD20 and treatments that either neutralize BLyS or cause B cells to migrate out of their protective microenvironment have been shown to be essential for effective B cell depletion in mouse models. ${ }^{37}$ Since anti-BLyS agents are already in clinical trials they could become available for such combination studies. However, evaluation in additional pre-clinical models of autoimmunity would seem a logical next step. TACI-Ig which blocks both BLyS and APRIL might be even more effective (or even more toxic).

3. What is the long-term toxicity of rituximab? Although we have data on repeated administration of rituximab, the number of patient gets smaller with each additional course. Are these studies selectively following patients who do well, and giving us a false sense of security? Long-term follow-up where a high percentage of patients are retained is needed. This might have to be done through some of the large cohorts or registries.

4. How good is rituximab at preventing damage? From the REFLEX trial we know that patients receiving rituximab have less progression of radiographic damage compared to patients receiving placebo, but how doe rituximab compare to alternative agents such as anti-TNFs or abatacept? Because of difficulties comparing results from one trial to the next, only a head-to-head comparison will answer this question. Certainly, a head-to-head trial would be needed to consider putting rituximab on par with anti-TNFs as a first line biologic for methotrexate inadequate responders.

5. Does rituximab predispose to PML? Because of the rarity of PML, clinical trial data will probably (we hope) not be able to answer this question. Data from large registries might eventually provide an answer, but will take years to become available. In the meantime it would be especially helpful to have information on how rituximab affects $\mathrm{T}$ cell migration into the CSF. We know that the number of $\mathrm{T}$ cells in the CSF of multiple sclerosis patients drops dramatically after starting treatment with natalizumab, in some individuals even lower than in patients with non-inflammatory neurological disease.$^{92}$ Moreover, the ration of CD4/CD8 T cells in CSF of nataizumab-treated multiple sclerosis patients also drops dramatically and becomes as low as in the CSF from HIV patients. ${ }^{93}$ Similar studies with rituximab would be extremely interesting.

6. How should immunizations be handled? As discussed above humoral responses to immunization can be inhibited after treatment with rituximab. Certainly, vaccines should be administered before the initial course of rituximab, if possible. This is particularly important for the pneumococcal vaccine and other vaccines that may not have to be re-administered for many years, but what about the flu vaccine that needs to be given every year? 
At 12 weeks post rituximab the response to flu vaccine appears is markedly blunted. By 6 months post rituximab response to tetanus, which like flu is a $\mathrm{T}$ cell dependent recall antigen, returns. How much earlier a response might have been seen and whether responses to influenza vaccine would have also return by 6 months are not clear. Additional studies evaluating humoral response to flu vaccine at various times after treatment with rituximab are needed.

7. Can a subset of patients that responds well to rituximab be identified? A biomarker identifying responders or non-responders would be an enormous breakthrough and would allow much more efficient use of rituximab. As discussed above some parameters correlating with response have been identified in small series. More sophisticated analyses of B cell subsets are now available and may provide a much clearer picture of B cell homeostatis after rituximab. ${ }^{10}$ However, technologies allowing better characterization of antigen-specific B cells would also be useful but these are still in development. There have been rapid advances in technology for proteomic and genomic studies and these should be readily applicable to the identification of a biomarker for responders and have the virtue that samples can easily be shipped to central labs. ${ }^{94-97}$ For all of these studies large patient cohorts and careful follow-up will be essential.

\section{Disclosures}

Dr Looney has been a consultant for Genentech, IDEC/Biogen, Roche, Centocor, Wyeth, Bristol-Myers-Squib, Proteolix, and Amgen.

\section{References}

1. Edwards JC, Cambridge G. Rheumatoid arthritis: the predictable effect of small immune complexes in which antibody is also antigen. $\mathrm{Br} \mathrm{J}$ Rheumatol. 1998;37(2):126-130.

2. Edwards JC, Cambridge G, Abrahams VM. Do self-perpetuating B lymphocytes drive human autoimmune disease? Immunology. 1999;97(2):188-196.

3. Zvaifler NJ. The immunopathology of joint inflammation in rheumatoid arthritis. Adv Immunol. 1973;16(0):265-336.

4. Abrahams VM, Cambridge G, Lydyard PM, Edwards JC. Induction of tumor necrosis factor alpha production by adhered human monocytes: a key role for Fcgamma receptor type IIIa in rheumatoid arthritis. Arthritis Rheum. 2000;43(3):608-616.

5. Petkova SB, Konstantinov KN, Sproule TJ, Lyons BL, Awwami MA, Roopenian DC. Human antibodies induce arthritis in mice deficient in the low-affinity inhibitory IgG receptor Fc gamma RIIB. $J$ Exp Med. 2006;203(2):275-280.

6. Kuhn KA, Kulik L, Tomooka B, et al. Antibodies against citrullinated proteins enhance tissue injury in experimental autoimmune arthritis. [see comment]. J Clin Invest. 2006;116(4):961-973.

7. Cassese G, Lindenau S, de Boer B, et al. Inflamed kidneys of NZB/W mice are a major site for the homeostasis of plasma cells. European Journal of Immunology. 2001;31(9):2726-2732.
8. Lund FE. Cytokine-producing B lymphocytes-key regulators of immunity. Curr Opin Immunol. 2008;20(3):332-338.

9. Wojciechowski W, Harris DP, Sprague F, et al. Cytokine-producing effector B cells regulate type 2 immunity to $\mathrm{H}$. polygyrus. [see comment]. Immunity. 2009;30(3):421-433.

10. Sanz I, Wei C, Lee FE-H, Anolik J. Phenotypic and functional heterogeneity of human memory B cells. Semin Immunol. 2008; 20(1):67-82.

11. Takemura S, Braun A, Crowson C, et al. Lymphoid neogenesis in rheumatoid synovitis. J Immunol. 2001;167(2):1072-1080.

12. Moyron-Quiroz JE, Rangel-Moreno J, Kusser K, et al. Role of inducible bronchus associated lymphoid tissue (iBALT) in respiratory immunity.[see comment]. Nat Med. 2004;10(9):927-934.

13. Rangel-Moreno J, Carragher DM, Misra RS, et al. B cells promote resistance to heterosubtypic strains of influenza via multiple mechanisms. J Immunol. 2008;180(1):454-463.

14. O'Neill SK, Shlomchik MJ, Glant TT, Cao Y, Doodes PD, Finnegan A. Antigen-specific B cells are required as APCs and autoantibodyproducing cells for induction of severe autoimmune arthritis. J Immunol. 2005;174(6):3781-3788.

15. Takemura S, Klimiuk PA, Braun A, Goronzy JJ, Weyand CM. T cell activation in rheumatoid synovium is B cell dependent. JImmunol. 2001;167(8):4710-4718.

16. Eming R, Nagel A, Wolff-Franke S, Podstawa E, Debus D, Hertl M. Rituximab exerts a dual effect in pemphigus vulgaris.[see comment]. J Investig Dermatol. 2008;128(12):2850-2858.

17. Edwards JCW, Szczepanski L, Szechinski J, et al. Efficacy of B-cell-targeted therapy with rituximab in patients with rheumatoid arthritis.[see comment]. N Engl J Med. 2004;350(25):2572-2581.

18. Emery P, Fleischmann R, Filipowicz-Sosnowska A, et al. The efficacy and safety of rituximab in patients with active rheumatoid arthritis despite methotrexate treatment: results of a phase IIB randomized, double-blind, placebo-controlled, dose-ranging trial.[see comment]. Arthritis Rheum. 2006;54(5):1390-1400.

19. Cohen SB, Emery P, Greenwald MW, et al. Rituximab for rheumatoid arthritis refractory to anti-tumor necrosis factor therapy: Results of a multicenter, randomized, double-blind, placebo-controlled, phase III trial evaluating primary efficacy and safety at twenty-four weeks. Arthritis Rheum. 2006;54(9):2793-2806.

20. Leandro MJ, Edwards JCW, Cambridge G. Clinical outcome in 22 patients with rheumatoid arthritis treated with B lymphocyte depletion. [see comment]. Ann Rheum Dis. 2002;61(10):883-888.

21. Keystone E, Emery P, Peterfy CG, et al. Rituximab inhibits structural joint damage in patients with rheumatoid arthritis with an inadequate response to tumour necrosis factor inhibitor therapies. Ann Rheum Dis. 2009;68(2):216-221.

22. Cohen S, Keystone E, Genovese M, et al. Continued inhibition of structural damage in rheumatoid arthritis patients treated with rituximab at 2 years: REFLEX Study. Available at: http://acr.confex. com/acr/2008/webprogram/. 2008; Abstract 368.

23. Cambridge G, Leandro MJ, Edwards JCW, et al. Serologic changes following B lymphocyte depletion therapy for rheumatoid arthritis. Arthritis Rheum. 2003;48(8):2146-2154.

24. Cambridge G, Stohl W, Leandro MJ, Migone T-S, Hilbert DM, Edwards JCW. Circulating levels of B lymphocyte stimulator in patients with rheumatoid arthritis following rituximab treatment: relationships with B cell depletion, circulating antibodies, and clinical relapse. Arthritis Rheum. 2006;54(3):723-732.

25. Keystone E, Fleischmann R, Emery P, et al. Efficacy and safety of repeat treatment courses of rituximab (RTX) in RA patients (pts) with Inadequate response (IR) to tumor necrosis factor (TNF) inhibitors: long-term experience from the REFLEX study. Available at: http://acr. confex.com/acr/2008/webprogram/. 2008; Abstract 367.

26. Thurlings RM, Vos K, Gerlag DM, Tak PP. Disease activity-guided rituximab therapy in rheumatoid arthritis: the effects of re-treatment in initial nonresponders versus initial responders. Arthritis and Rheumatism. 2008;58(12):3657-3664. 
27. Owczarczyk K, Maizus K, Roehrs T, et al. The clinical efficacy of repeated courses of rituximab and the kinetics of $\mathrm{B}$ cell depletion in primary rituximab non-responders. Available at: http://acr.confex. com/acr/2008/webprogram/. 2008; Abstract 1002.

28. Teng Y, Tekstra J, Breedveld F, Lafeber F, Bijlsma J, van Laar J. Rituximab fixed retreatment versus on-demand retreatment in refractory rheumatoid arthritis: comparison of two B cell depleting treatment strategies. AnnRheum Dis. 2009;68:1075-1077.

29. Smolen JS, Keystone EC, Emery P, et al. Consensus statement on the use of rituximab in patients with rheumatoid arthritis. Ann Rheum Dis. 2007;66(2):143-150.

30. Leandro MJ, Cambridge G, Ehrenstein MR, Edwards JCW. Reconstitution of peripheral blood B cells after depletion with rituximab in patients with rheumatoid arthritis.[see comment]. Arthritis Rheum 2006;54(2):613-620.

31. Roll P, Palanichamy A, Kneitz C, Dorner T, Tony H-P. Regeneration of B cell subsets after transient B cell depletion using anti-CD20 antibodies in rheumatoid arthritis. Arthritis Rheum. 2006;54(8):2377-2386.

32. Roll P, Dorner T, Tony H-P. Anti-CD20 therapy in patients with rheumatoid arthritis: predictors of response and $\mathrm{B}$ cell subset regeneration after repeated treatment. Arthritis Rheum. 2008;58(6):1566-1575.

33. Vallerskog T, Heimburger M, Gunnarsson I, et al. Differential effects on BAFF and APRIL levels in rituximab-treated patients with systemic lupus erythematosus and rheumatoid arthritis. Arthritis Res Ther. 2006;8(6):R167.

34. Teng YKO, Levarht EWN, Toes REM, Huizinga TWJ, van Laar JM. Residual inflammation after rituximab treatment is associated with sustained synovial plasma cell infiltration and enhanced B cell repopulation. Ann Rheum Dis. 2009;68:1011-1016.

35. Dass S, Rawstron AC, Vital EM, Henshaw K, McGonagle D, Emery P Highly sensitive B cell analysis predicts response to rituximab therapy in rheumatoid arthritis. Arthritis Rheum. 2008;58(10):2993-2999.

36. Mei H, Reiter K, Froelich D, Tony H-P, Radbruch A, Dorner T. Persistent Generation of Plasmablasts in B cell depleted Patients with Rheumatoid Arthritis. Available at: http://acr.confex.com/acr/2008/ webprogram/. 2008; Abstract 765.

37. Gong Q, Ou Q, Ye S, et al. Importance of cellular microenvironment and circulatory dynamics in B cell immunotherapy. J Immunol. 2005;174(2):817-826.

38. Vos K, Thurlings RM, Wijbrandts CA, van Schaardenburg D, Gerlag DM, Tak PP. Early effects of rituximab on the synovial cell infiltrate in patients with rheumatoid arthritis. [see comment]. Arthritis Rheum. 2007;56(3):772-778.

39. Teng YKO, Levarht EWN, Hashemi M, et al. Immunohistochemical analysis as a means to predict responsiveness to rituximab treatment. Arthritis Rheum. 2007;56(12):3909-3918.

40. Kavanaugh A, Rosengren S, Lee SJ, et al. Assessment of rituximab's immunomodulatory synovial effects (ARISE trial). 1: clinical and synovial biomarker results. Anne Rheum Dis. 2008;67(3):402-408.

41. Thurlings RM, Vos K, Wijbrandts CA, Zwinderman AH, Gerlag DM, Tak PP. Synovial tissue response to rituximab: mechanism of action and identification of biomarkers of response. Ann Rheum Dis. 2008;67(7):917-925.

42. Rosengren S, Wei N, Kalunian KC, Zvaifler NJ, Kavanaugh A, Boyle DL. Elevated autoantibody content in rheumatoid arthritis synovia with lymphoid aggregates and the effect of rituximab. Arthritis ResTher. 2008;10(5):R105.

43. Brandon S, Kistler P, Jenunet FHI. Intravenous Administration of Human Gammaglobulin. Vox Sanguis. 1962;7:157-174.

44. Lowndes S, Darby A, Mead G, Lister A. Stevens-Johnson syndrome after treatment with rituximab. Ann Oncol. 2002;13(12):1948-1950.

45. Allen KP, Funk AJ, Mandrell TD. Toxic epidermal necrolysis in two rhesus macaques (Macaca mulatta) after administration of rituximab. Comp Med. 2005;55(4):377-381.

46. Joly P, Mouquet H, Roujeau JC, et al. A single cycle of rituximab for the treatment of severe pemphigus.[see comment]. $N$ Engl JMed. 2007;357(6):545-552.
47. Khalili K, White MK, Lublin F, Ferrante P, Berger JR. Reactivation of JC virus and development of PML in patients with multiple sclerosis. Neurology. 2007;68(13):985-990.

48. Berger JR, Koralnik IJ. Progressive multifocal leukoencephalopathy and natalizumab - unforeseen consequences.[comment]. N Engl JMed. 2005;353(4):414-416

49. Koralnik IJ. Progressive multifocal leukoencephalopathy revisited: Has the disease outgrown its name? Ann Neurol. 2006;60(2):162-173.

50. FDA. FDA ALERT [8/2008]: The FDA has recently received information from the manufacturer about two new cases of progressive multifocal leukoencephalopathy (PML) in patients receiving Tysabri monotherapy for multiple sclerosis in Europe. 2008.

51. FDA. FDA Public Health Advisory: Suspended marketing of Tysabri (natalizumab). Available at: http://www.fda.gov/cder/drug/advisory/ natalizumab.htm. 2007.

52. Genentech. Voluntary U.S. market withdrawal of Raptiva ${ }^{\circledR}$ (efalizumab). Available at: http://www.fda.gov/medwatch/safety/2009/Raptiva_ Withdrawal_DHCP_2009-04-08_FINAL.pdf. 2009.

53. Steurer M, Clausen J, Gotwald T, et al. Progressive multifocal leukoencephalopathy after allogeneic stem cell transplantation and posttransplantation rituximab. Transplantation. 2003;76(2):435-436.

54. Goldberg SL, Pecora AL, Alter RS, et al. Unusual viral infections (progressive multifocal leukoencephalopathy and cytomegalovirus disease) after high-dose chemotherapy with autologous blood stem cell rescue and peritransplantation rituximab. [see comment]. Blood. 2002;99(4):1486-1488.

55. Matteucci P, Magni M, Di Nicola M, Carlo-Stella C, Uberti C, Gianni AM. Leukoencephalopathy and papovavirus infection after treatment with chemotherapy and anti-CD20 monoclonal antibody. [comment]. Blood. 2002;100(3):1104-1105.

56. Pelosini M, Focosi D, Rita F, et al. Progressive multifocal leukoencephalopathy: report of three cases in HIV-negative hematological patients and review of literature. Ann Hematol. 2008;87(5):405-412.

57. FDA. FDA ALERT [12/2006]: This Alert highlights important emerging safety information about Rituxan. Two patients have died after being treated with Rituxan for systemic lupus erythematosus (SLE). Available at: http://www.fda.gov/cder/drug/InfoSheets/HCP/rituximab.pdf. 2006.

58. Genentech. New safety information regarding Rituxan ${ }^{\circledR}$ (rituximab): a case of PML in a patient with RA. Available at: http://www.fda.gov/ medwatch/safety/2008/rituxan_DHCP_Final\%209411700.pdf. 2008.

59. Harris HE. Progressive multifocal leucoencephalopathy in a patient with systemic lupus erythematosus treated with rituximab. Rheumatology. 2008;47(2):224-225.

60. Calabrese LH, Molloy ES, Huang D, Ransohoff RM. Progressive multifocal leukoencephalopathy in rheumatic diseases: evolving clinical and pathologic patterns of disease. Arthritis Rheum. 2007;56(7): 2116-2128.

61. Calabrese LH, Molloy ES. Progressive multifocal leucoencephalopathy in the rheumatic diseases: assessing the risks of biological immunosuppressive therapies. Ann Rheum Dis. 2008;67 Suppl 3:iii64-65.

62. Boren EJ, Cheema GS, Naguwa SM, Ansari AA, Gershwin ME. The emergence of progressive multifocal leukoencephalopathy (PML) in rheumatic diseases. J Autoimmun. 2008;30(1-2):90-98.

63. Looney RJ, Diamond B, Holers VM, et al. Guidelines for assessing immunocompetency in clinical trials for autoimmune diseases. Clin Immunol. 2007;123(3):235-243.

64. Looney RJ, Srinivasan R, Calabrese LH. The effects of rituximab on immunocompetency in patients with autoimmune disease.[see comment]. Arthritis Rheum. 2008;58(1):5-14.

65. Salliot C, Dougados M, Gossec L. Risk of serious infections during rituximab, abatacept and anakinra treatments for rheumatoid arthritis: meta-analyses of randomised placebo-controlled trials. Ann RheumDis. 2009;68(1):25-32.

66. Keystone E, Fleischmann R, Emery P, et al. Safety and efficacy of additional courses of rituximab in patients with active rheumatoid arthritis: an open-label extension analysis. Arthritis Rheum. 2007; 56(12):3896-3908. 
67. Yeo W, Chan TC, Leung NWY, et al. Hepatitis B virus reactivation in lymphoma patients with prior resolved hepatitis B undergoing anticancer therapy with or without rituximab. J Clin Oncol. 2009;27(4):605-611.

68. Al-Taie OH, Mork H, Gassel AM, Wilhelm M, Weissbrich B, Scheurlen M. Prevention of hepatitis B flare-up during chemotherapy using lamivudine: case report and review of the literature. Annf Hematol. 1999;78(5):247-249.

69. Lau GKK, Yiu HHY, Fong DYT, et al. Early is superior to deferred preemptive lamivudine therapy for hepatitis B patients undergoing chemotherapy.[see comment]. Gastroenterology. 2003;125(6): 1742-1749.

70. Simpson ND, Simpson PW, Ahmed AM, et al. Prophylaxis against chemotherapy-induced reactivation of hepatitis B virus infection with Lamivudine. J Clin Gastroenterol. 2003;37(1):68-71.

71. Calabrese LH, Zein NN, Vassilopoulos D. Hepatitis B virus (HBV) reactivation with immunosuppressive therapy in rheumatic diseases: assessment and preventive strategies. Ann Rheum Dis. 2006;65(8): 983-989.

72. Sansonno D, De Re V, Lauletta G, Tucci FA, Boiocchi M, Dammacco F. Monoclonal antibody treatment of mixed cryoglobulinemia resistant to interferon alpha with an anti-CD20. Blood. 2003;101(10):3818-3826.

73. Zaja F, De Vita S, Mazzaro C, et al. Efficacy and safety of rituximab in type II mixed cryoglobulinemia. Blood. 2003;101(10):3827-3834.

74. Popa C, Leandro MJ, Cambridge G, Edwards JCW. Repeated B lymphocyte depletion with rituximab in rheumatoid arthritis over 7 yrs. Rheumatology. 2007;46(4):626-630.

75. Doran MF, Crowson CS, Pond GR, O'Fallon WM, Gabriel SE. Predictors of infection in rheumatoid arthritis. Arthritis Rheum. 2002;46(9):2294-2300.

76. Franklin J, Lunt M, Bunn D, Symmons D, Silman A. Risk and predictors of infection leading to hospitalisation in a large primary-care-derived cohort of patients with inflammatory polyarthritis. Anne Rheum Dis. 2007;66(3):308-312.

77. Wolfe F, Caplan L, Michaud K. Treatment for rheumatoid arthritis and the risk of hospitalization for pneumonia: associations with prednisone, disease-modifying antirheumatic drugs, and anti-tumor necrosis factor therapy. Arthritis and Rheumatism. 2006;54(2):628-634.

78. Lack G, Ochs HD, Gelfand EW. Humoral immunity in steroid-dependent children with asthma and hypogammaglobulinemia. J Pediatr. 1996;129(6):898-903.

79. Gonzalez-Stawinski GV, Yu PB, Love SD, Parker W, Davis RD Jr. Hapten-induced primary and memory humoral responses are inhibited by the infusion of anti-CD20 monoclonal antibody (IDEC-C2B8, Rituximab). Clin Immunol. 2001;98(2):175-179.

80. van der Kolk LE, Baars JW, Prins MH, van Oers MHJ. Rituximab treatment results in impaired secondary humoral immune responsiveness. Blood. 2002;100(6):2257-2259

81. Bearden CM, Agarwal A, Book BK, et al. Rituximab inhibits the in vivo primary and secondary antibody response to a neoantigen, bacteriophage phiX174. Am J Transplant. 2005;5(1):50-57.

82. Albert D, Dunham J, Khan S, et al. Variability in the biological response to anti-CD20 B cell depletion in systemic lupus erythaematosus. AnnRheum Dis. 2008;67(12):1724-1731.
83. Gelinck LBS, Teng YKO, Rimmelzwaan GF, van den Bemt BJF, Kroon FP, van Laar JM. Poor serological responses upon influenza vaccination in patients with rheumatoid arthritis treated with rituximab. AnnRheum Dis. 2007;66(10):1402-1403.

84. Oren S, Mandelboim M, Braun-Moscovici Y, et al. Vaccination against influenza in patients with rheumatoid arthritis: the effect of rituximab on the humoral response. Ann Rheum Dis. 2008;67(7):937-941.

85. Bingham C, Looney R, Deodhar A, et al. Results from a controlled clinical trial (SIERRA) to evaluate primary and recall responses to immunizations in RA patients treated with rituximab. Available at: http://acr.confex.com/acr/2008/webprogram/. 2008; Abstract 1999.

86. Dunleavy K, Hakim F, Kim HK, et al. B-cell recovery following rituximab-based therapy is associated with perturbations in stromal derived factor-1 and granulocyte homeostasis. Blood. 2005;106(3): 795-802.

87. Marotte H, Paintaud G, Watier H, Miossec P. Rituximab-related late-onset neutropenia in a patient with severe rheumatoid arthritis. Ann Rheum Dis. 2008;67(6):893-894.

88. Genovese M, Breedveld F, Emery P, et al. Safety Of Other Biologic Therapies Following Rituximab Treatment In RA Patients. Available at: http://acr.confex.com/acr/2008/webprogram/. 2009; Abstract 1671.

89. McGonagle D, Tan AL, Madden J, Taylor L, Emery P. Rituximab use in everyday clinical practice as a first-line biologic therapy for the treatment of DMARD-resistant rheumatoid arthritis.[see comment]. Rheumatology. 2008;47(6):865-867.

90. Emery P, Rigby W, Combe B, et al. Efficacy and Safety of Rituximab (RTX) as First-Line Biologic Therapy in Patients (pts) with Active Rheumatoid Arthritis (RA): Results of a Phase III Randomized Controlled Study (SERENE). Available at: http://acr.confex.com/ acr/2008/webprogram/. 2008; Abstract 364.

91. Looney RJ, Anolik JH, Campbell D, et al. B cell depletion as a novel treatment for systemic lupus erythematosus: a phase I/II dose-escalation trial of rituximab. Arthritis Rheum. 2004;50(8):2580-2589.

92. Stuve O, Marra CM, Jerome KR, et al. Immune surveillance in multiple sclerosis patients treated with natalizumab.[see comment]. AnnNeurol. 2006;59(5):743-747.

93. Stuve O, Marra CM, Bar-Or A, et al. Altered CD4+/CD8+ T-cell ratios in cerebrospinal fluid of natalizumab-treated patients with multiple sclerosis. [see comment]. ArchNeurol. 2006;63(10):1383-1387.

94. Balboni I, Limb C, Tenenbaum JD, Utz PJ. Evaluation of microarray surfaces and arraying parameters for autoantibody profiling. Proteomics. Sep 2008;8(17):3443-3449

95. Chen Z, Tabakman SM, Goodwin AP, et al. Protein microarrays with carbon nanotubes as multicolor Raman labels. Nat Biotechnol. 2008;26(11):1285-1292.

96. Kattah MG, Coller J, Cheung RK, Oshidary N, Utz PJ. HIT: a versatile proteomics platform for multianalyte phenotyping of cytokines, intracellular proteins and surface molecules. Nat Med. 2008;14(11): 1284-1289.

97. Chaussabel D, Quinn C, Shen J, et al. A modular analysis framework for blood genomics studies: application to systemic lupus erythematosus.[see comment]. Immunity. 2008;29(1):150-164.
Open Access Rheumatology Research and Reviews

\section{Publish your work in this journal}

Open Access Rheumatology Research and Reviews is an international, peer-reviewed, open access journal, publishing all aspects of clinical and experimental rheumatology in the clinic and laboratory including the following topics: Pathology, pathophysiology of rheumatological diseases; Investigation, treatment and management of rheumatological

\section{Dovepress}

diseases; Clinical trials and novel pharmacological approaches for the treatment of rheumatological disorders. The manuscript management system is completely online and includes a very quick and fair peerreview system, which is all easy to use. Visit http://www.dovepress.com/ testimonials.php to read real quotes from published authors. 